\title{
Barriers and facilitators of translating health research findings into policy in sub-Saharan Africa: A Scoping Review
}

\author{
Florence Upenyu Damba (1) ${ }^{2 凶}$, Ntombifikile Gloria Mtshali2,3 \& \\ Moses John Chimbari1,2,3
}

Despite efforts made by sub-Saharan Africa (SSA) countries to promote evidence-informed health policymaking, translating research evidence into policy remains a very challenging task fraught with many barriers. However, to achieve the goal of making more evidence-informed decisions to improve health, it is critical to overcome the barriers to the translation of research into policy. This paper provides an overview of the barriers and facilitators of translating research into policy in SSA countries to understand why research findings are sometimes not translated into policy and makes suggestions for improving the situation. Arksey and O'Malley's five-step methodological framework guided the scoping review process. Primary research literature published in English between January 2010 and March 2021 was systematically searched using PubMed, Google Scholar, Web of Science and EBSCO host search engines. We focused on articles that reported on the barriers to and facilitators of translating research findings into policy. Two hundred and twenty-three articles were identified but 162 articles met the eligibility criteria. Of those that met the eligibility criteria, 73 were excluded after reading the title and abstract. After title and abstract screening, a further 70 articles were excluded thus remaining with only 19 articles from 16 SSA countries that were given a full review through data extraction and thematic analysis. The most common barriers identified were limited capacity by policymakers to use evidence, inaccessibility of research evidence, lack of high-quality usable evidence and use of policy briefs alone. Although translation of research findings into policy is fraught with a multitude of barriers, there are means to overcome them such as the availability of research results, strengthened capacity for evidence use, the establishment of a department of research within the Ministry of Health, appropriate packaging of research results, use of policy briefs, stakeholder feedback meetings and annual research dissemination conferences where policy briefs are discussed and distributed. Where funding is limited research should be policy driven instead of open-ended to avoid wasting resources. It is imperative to have a comprehensive approach to reduce barriers whilst enhancing facilitators that may improve the translation of research findings into policy.

\footnotetext{
${ }^{1}$ Great Zimbabwe University, P.O. Box 1235, Masvingo, Zimbabwe. ${ }^{2}$ Present address: School of Nursing and Public Health, College of Health Sciences, Howard College, University of KwaZulu-Natal, 269 Mazisi Kunene Road, Berea, Durban 4041, South Africa. ${ }^{3}$ These authors contributed equally: Ntombifikile

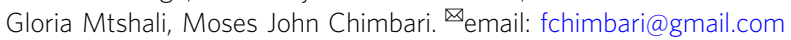




\section{Introduction}

$s$ the global health community is pushing for ambitious goals of universal health coverage and health equity in the post-2015 development era, there is an increasing interest worldwide to ensure evidence-informed health policymaking as a means to improve health systems performance (El-Jardali et al., 2014). The 2005 Fifty-eighth World Health Assembly Resolution (WHA58.34 Ministerial Summit on Health Research) triggered unprecedented global interest in the promotion of the use of research evidence to inform policymaking in the health sector by acknowledging that high quality research and the generation and application of knowledge are critical for achieving internationally agreed health related goals including those contained in the United Nations Sustainable Development Goals (SDGs), especially in low-and middle- income countries (LMICs) (Uneke et al., 2017). The inability for health systems in many low- and middle- income countries (LMICs) to effectively use evidence to inform decisions and interventions is cited as a major obstacle to the achievement of the Millennium Development Goals (Panisset et al., 2012; Lavis et al., 2010).

Evidence-informed policies coupled with well-executed implementation and monitoring are likely to enable the achievement of health-related sustainable development goals (e.g. end hunger, achieve food security and improved nutrition and promote sustainable agriculture), as well as a reduction in burden of disease (Hanney et al., 2020, Lavis et al., 2009). Numerous global health initiatives have promoted the application of knowledge into policy yet the use of evidence by policymakers to inform programs aligned with population needs remains an important public health challenge (Smits and Denis, 2014). Even the highest quality evidence will have no impact unless it is incorporated into decision-making. Poorly informed decisionmaking particularly in LMICs is one of the reasons why healthcare services fail to reach vulnerable populations, why health indicators are poor and why many countries failed to achieve the Millennium Development Goals (MDGs) whose agenda is now being pushed through Sustainable Development Goals (SDGs).

Much research already exists on evidence uptake. In their systematic review looking at facilitators and barriers to uptake of evidence in policymaking, Oliver et al, describe an "explosion of research in the area" (Oliver et al., 2014) and since then more studies on the matter have been conducted. Despite the efforts by sub-Saharan Africa (SSA) countries to promote evidenceinformed health policymaking, translating research into policy remains fraught with many barriers. To achieve the goal of making more evidence-informed decisions to improve health outcomes, it is critical to overcome the barriers to the translation of research into policy. This review sought to identify barriers and facilitators of translating research into policy in SSA countries with a view to improve translation of health research findings into policy.

\section{Methods}

The methodology for this scoping review was based on Arksey and O'Malley scoping review framework (Arksey and O'malley, 2005). Accordingly, we followed five key phases: (1) identifying the research question, (2) identifying relevant studies, (3) study selection, (4) charting the data, and (5) collating, summarizing, and reporting the results. The optional 'consultation exercise' of the framework was not conducted.

Identifying the research question. The review was guided by the research question "What are the barriers to and facilitators of the translation of health research into policy in sub-Saharan Africa?"
Identifying relevant studies. In this review, only studies focusing on the barriers and facilitators of evidence-informed policymaking were included. Selection for eligible studies was conducted through searches in PubMed, Web of Science and EBSCOhost. Grey literature was also searched using the Google Scholar search engine. The search period was January 2010-March 2021. Articles published in languages other than English and those not highlighting barriers and facilitators were excluded. The search used the "AND" and "OR" Boolean operators with search terms "Knowledge translation" OR "Knowledge transfer" AND "Policy" AND "Evidence" AND "Research" AND "Health" AND "Barriers" AND "Facilitators" OR "Enablers". A country filter was also applied to limit the search to 48 countries in SSA.

Title and abstract relevance. For the first level of screening, only the title and abstract of each citation were screened. Titles for which an abstract was not available were included for subsequent review of the full article in the data characterization phase.

Data characterization. All citations deemed relevant after title and abstract screening were considered for subsequent review of the full text articles. A form was developed by the authors to confirm relevance and to extract characteristics including publication details (author (s) and year of publication), study objectives, study focus, country of study and themes of barriers and facilitators identified and the information was entered onto a data extraction template (Table 1). The studies had different designs namely: qualitative, quantitative and mixed methods. For synthesis, the extracted information was grouped into five themes, namely: organizations and resources, contact and collaboration, research and researcher characteristics, policy and policymaker and government characteristics. We followed the Preferred Reporting Items for Systematic Reviews and Meta-Analyses (PRISMA) guidelines (Fig. 1) adapted from Moher et al. for the inclusion criteria (Moher et al., 2009). The original search yielded 223 potentially relevant articles including duplicates. After sixty (61) duplicate articles were removed 162 articles met the eligibility criteria. Seventy-three (73) articles were removed based on abstract and title relevance. A further seventy (70) articles were removed because discourse on barriers and facilitators of translation of research into policy was not apparent in them. Only 19 articles from 16 SSA countries that prominently addressed barriers and facilitators were fully reviewed.

Data extraction and synthesis. All the relevant data was entered onto a predesigned data extraction sheet (Table 1) which was piloted on several articles and refined accordingly. Data extracted included: publication details, year of study, study objectives, study focus, country of study and themes of barriers and facilitators identified. Two members of the research team performed the data extraction with the third researcher double checking the extracted data for accuracy and completeness. Discrepancies in the data collected were resolved through iterative discussions with reference to the original publication for clarification.

\section{Data analysis}

Methodological rigour of included studies. In the scoping review, data were analyzed using thematic content analysis. An initial coding framework based on the taxonomy of barriers and facilitators on the use of evidence by policymakers identified by Oliver et al. was developed (Oliver et al., 2014). We independently reviewed the coding framework and applied it to data from the 19 studies. Factors which affected evidence use were coded as barriers or facilitators against a predefined list of factors which 
Table 1 Summary of reviewed studies.

\section{Author and} publication year

El-Jardali et al. (2014)

Study objectives

To understand facilitators that suppor knowledge translation platforms work and challenges.

Ezenwaka et al. To explore barriers and identify (2020)
Qualitative, cross-sectional study 68 participants from tertiary institutions and health organizations- (33 producers of evidence-researchers and 35 policy makers (senior healthcare managers and programme officers), data collected through group discussions in two workshops.
Kalbarczyk et al. To describe needs and barriers in

(2021)

Accepted 02/

$12 / 20$

Published 01/

$03 / 21$ knowledge translation specific to academic institutions in LMICs.
Kumar et al.

(2020)
To understand the role of evidence in how decisions are made for community health financing and policy at national and global levels.
Qualitative cross-sectional study National and global funders, policymakers and researchers; 43 in-depth key informant interviews.
Nigeria

Burkina Faso, Cameroon, Central African Republic, Ethiopia, Nigeria,

Sudan, Uganda and Zambia.
Qualitative, cross- sectional study.
Purposive sampling; 47 key informants stakeholders from 10 KTPs: 17 semiand observation of deliberations at the
Qualitative study

Document review

Key informant interviews with 11 representatives from academic institutions and 7 policymakers from Ministries of Health
Republic of Congo, Ethiopia and Nigeria.

Ethiopia, Kenya, Malawi and Mozambique

\footnotetext{
Oronje et al. To inform and enrich ongoing and (2019) future efforts to strengthen capacity for evidence use.
}

Mixed method, cross-sectional descriptive study

Technical staff (mid-level policy makers) top-level policymakers and senior researchers; Data collected through indepth interviews and semi-structured questionnaire; pre-post tests for the training workshops.
Kenya and Malawi

\section{Barriers and facilitators identified}

Barriers: gaps in research production, limited alignment of research with regional priorities and lack of skills among research users to acquire, assess, adapt and use research evidence. Facilitators: use of evidence briefs, networking between researchers and policymakers, increasing funding opportunities, technical support, strengthening the capacity of policymakers, stakeholders, and researchers to engage in evidenceinformed health policymaking and incentivizing researchers and research users.

Barriers: weak institutional research linkages between producers and users of evidence, poor capacity to undertake and use research evidence, poor functionality of research units and research ethics committees, poor government funding for research, weak Health Management Information System, political interference and nepotism, limited decision space of users of evidence and poor demand and support for research evidence Facilitators: existing relationships and linkage with the Health Policy Research Group, improved individual competence and organizational capacity for EIDM, good political will, increasing interest to integrate research evidence in decisionmaking processes among users and producers of evidence, active engagement of decision-makers in the Ministry of Economic Planning and Budgeting to facilitate the release of budgetary allocations to health, availability of donors/partners, willingness to create a knowledge translation forum between users and producers of evidence.

Barriers: limited institutional resources to scale up research-related activities, lack of skills to conduct knowledge translation, challenges procuring internal and external resources to conduct knowledge translation, lack of recognition (e.g., incentives or rewards) for successfully conducting knowledge translation and policymakers' lack of capacity to use data to make change.

Facilitators: diverse stakeholder engagement, individual and institutional relationships with policymakers, soft skills to navigate the policy process and engage with policymakers and internal and external networks.

Barriers: lack of high- quality usable evidence, available evidence not generalizable, promotion of donor priorities over local ones and limitations in capacity to evaluate and apply the evidence meaningfully.

Facilitators: Improved data quality, increase in relevance of evidence and increased capacity for evidence use Barriers: inadequate numbers of staff, weak or lack of skills in EIDM, weak institutional linkages between the $\mathrm{MOHs}$ and the research institutions, limited funding.

Facilitators: involving top-level policymakers in the selection of technical staff to be trained on the use of evidence, training and mentorship activities increased participants' awareness, technical knowledge and or skills, establishment of a division of Research and Development to support MOH's use of research evidence, introduction of a budget line by Kenya $\mathrm{MOH}$ for the Research and Development unit to facilitate evidence use in the ministry. 


\section{Table 1 (continued)}

\section{Author and publication year}

Uneke et al. (2017)

\section{Study objectives}

To assess the perception of $\mathrm{MNCH}$ policymakers regarding the barriers and facilitators to use of research evidence in policymaking in Nigeria.
Mwendera et al. To assess enhancing factors and (2016)

Naude et al. (2015)

Schleiff et al. (2020) barriers of research utilization for malaria policy development in Malawi.
Qualitative study

In-depth interviews, purposive sampling and snowballing-39 key informants (malaria researchers, policy makers, program managers, and key stakeholders). Purposive sampling and snowballing techniques.
To describe the different contexts in which health policies are formulated and identify the facilitators and barriers to demanding research evidence.
Qualitative study 9 in-depth interviews and 4 focus group South Africa purposively sampled subnational (provincial and regional) government health programme managers.
Malawi

Ethiopia, Ghana Mozambique, Rwanda South Africa
To identify and describe enablers and countries.

\section{Qualitative}

Study

In-depth written case studies; interviews with key informants and document review.
Barriers and facilitators identified

Barriers: no systematic way/mechanism for use of research in maternal, new-bor and child health $(\mathrm{MNCH})$ intervention, inadequate capacity of the organisation to conduct research, no written policy that mandates staff to base their work on evidence, policymakers' indifference to research evidence, research priorities being donor-driven, poor dissemination of research results and lack of interaction fora for researchers and policymakers. Facilitators: capacity strengthening on use of research in policy formulation, policies to ensure appropriate budget allocations for research, policies toensure that any newly introduced policymust be accompanied with evidence, appropriate dissemination of research findings, use of policy briefs, allowing policymakers to determine areas of research based on needs, and establishment of an annual forum for presentation and consideration of research work/results for possible adoption and incorporation into policymaking process.

Barriers: lack of platforms for researcherpublic engagement, political influence, lack of research synthesis skills by policymakers, lack of trust in research findings by policymakers, lack of communication of research findings to policymakers, policymakers' lack of time to find and read research articles, research not addressing the country's needs, lack of collaboration between researchers and policymakers, poor dissemination of research findings, lack of collaboration among researchers and lack of malaria research repositories. Facilitators: establishment of knowledge translation platforms, political will, availability of local research findings and collaborations between researchers and policymakers

Barriers: research evidence not considered the main driver of policy decisions, research evidence frequently perceived as unavailable, inaccessible, ill-timed, or not applicable- not well-aligned with the health services, insufficient time, and capacity to translate evidence for policy decisions, contradictory research evidence and strong political influence. Facilitators: policymakers who are familiar with EIDM, willingness of policymakers to enhance skills in EIDM, collaboration and networking between researchers and policymakers, improved funding for policy relevant research, attention grabbing packaging of evidence, and having a repository with evidence summaries, use of policy briefs and policymakers flagging priority research areas.

Barriers: lack of training on database use; dysfunctionality of databases; language barriers or lack of communication processes within and between the $\mathrm{MOH}$ and other institutions and practices. Facilitators: incentivizing staff, aligning government policies with international declarations and goals, access to realtime data as well as share data across different agencies and partners, establishing a designated unit within a $\mathrm{MOH}$ or across multiple sectors of government and having ongoing, structured and accountable contact between civil servants (CSs), researchers and a range of other stakeholders and capacity strengthening and engagement of CSs. 


\section{Table 1 (continued)}

\section{Author and \\ publication year}

Ssengooba et al. (2011)

Young et al.

(2018)

To pilot and evaluate a programme of formalized dialogue between researchers and provincial health policymakers in South Africa.

Nabyonga-Orem

et al.

(2014a, 2014b) factors to uptake of evidence in the process of user fee abolition in Ugand

To explain why projects in some settings were perceived to have moved towards their stated objectives while others were perceived to have not done so well.
Shroff et at.

(2015)
Methods

Qualitative study

In-depth interviews with 30 purposively

selected researchers, policymakers and media practitioners.
Mixed methods study

Semi-structure interviews with project leaders, team members, policymakers, researchers and members of civil society groups; document review.
Nabyonga-Orem

et al.

(2014a, 2014b) explore the barriers and facilitatory actors to the uptake
Qualitative study

In-depth semi-structured interviews with policymakers and researcher buddies focus group discussions.

Mixed methods study

Theory driven and case study approach document review; 32 in-depth interviews with purposively selected participants from $\mathrm{MOH}$, Ministry of Finance (MOF) researchers, civil society and journalists.

Cameroon, Nigeria, and Zambia

Uganda

South Africa

.

-


Table 1 (continued)

\begin{tabular}{|c|c|c|c|c|}
\hline $\begin{array}{l}\text { Author and } \\
\text { publication year }\end{array}$ & Study objectives & Methods & Study location & Barriers and facilitators identified \\
\hline $\begin{array}{l}\text { Mapulanga et al. } \\
\text { (2019) }\end{array}$ & $\begin{array}{l}\text { To ascertain the health researchers' } \\
\text { involvement of health policy or } \\
\text { decision makers in knowledge } \\
\text { translation and exchange activities. }\end{array}$ & $\begin{array}{l}\text { Quantitative study } \\
\text { Questionnaires administered to } \\
\text { researchers and directors of health- } \\
\text { related organizations. }\end{array}$ & Malawi & $\begin{array}{l}\text { Barriers: researchers' lack of } \\
\text { communication skills, poor research } \\
\text { dissemination skills, researchers' lack of } \\
\text { technical capacity in policy processes, } \\
\text { lack of data needed for each step of the } \\
\text { policy processes, researchers' lack of } \\
\text { diverse political influences which drive } \\
\text { policy formulation or policy change. } \\
\text { Facilitators: appropriate packaging of } \\
\text { research results, use of social networks } \\
\text { and the institutionalisation of the use of } \\
\text { health research evidence. }\end{array}$ \\
\hline $\begin{array}{l}\text { Inguane et al. } \\
\text { (2020) }\end{array}$ & $\begin{array}{l}\text { Challenges and facilitators to } \\
\text { evidence- based decision-making for } \\
\text { maternal and child health in } \\
\text { Mozambique: district, municipal and } \\
\text { national case studies. }\end{array}$ & $\begin{array}{l}\text { Qualitative, case study } \\
24 \text { in-depth interviews; six case studies } \\
\text { examined at national level; document } \\
\text { review. }\end{array}$ & Mozambique & $\begin{array}{l}\text { Barriers: lack of national government } \\
\text { funding, a top-down approach to } \\
\text { decision-making, limited qualified human } \\
\text { resources, untimely dissemination of the } \\
\text { results, promotion of global priorities over } \\
\text { national ones, limited central government } \\
\text { funding, lack of participation of non- } \\
\text { health actors. } \\
\text { Facilitators: institutional investments in } \\
\text { resources for capacity strengthening, } \\
\text { communication and team building } \\
\text { strategies, access to electronic-based } \\
\text { routine health information systems (HIS) } \\
\text { data, collaborative decision-making at } \\
\text { health-sector regular meetings; } \\
\text { international NGOs' funding and logistical } \\
\text { support. }\end{array}$ \\
\hline $\begin{array}{l}\text { Cockcroft et al. } \\
\text { (2014) }\end{array}$ & $\begin{array}{l}\text { To describe the training of } \\
\text { parliamentarians in evidence-based } \\
\text { policymaking. }\end{array}$ & $\begin{array}{l}\text { Mixed method, case study } \\
27 \text { interviews with elected } \\
\text { representatives and members of } \\
\text { parliament. }\end{array}$ & Botswana & $\begin{array}{l}\text { Barriers: lack of good quality and relevant } \\
\text { evidence, use of jargon, lack of research } \\
\text { staff for Parliament and the inaccessibility } \\
\text { of research evidence. } \\
\text { Facilitator: strengthening the capacity of } \\
\text { staff to engage in evidence-informed } \\
\text { policymaking. }\end{array}$ \\
\hline $\begin{array}{l}\text { Hamel and } \\
\text { Schrecker } \\
\text { (2011) }\end{array}$ & $\begin{array}{l}\text { To gain insight into the factors that } \\
\text { affect the knowledge translation } \\
\text { performance of health professional } \\
\text { associations in LMICs }\end{array}$ & $\begin{array}{l}\text { Mixed method, case study } \\
\text { Data sources: in-depth interviews; } \\
\text { questionnaires; reports, newsletters and } \\
\text { newspapers articles; and informal } \\
\text { meetings with the office staff and } \\
\text { stakeholders of the ABSP. }\end{array}$ & Burkina Faso & $\begin{array}{l}\text { Barriers: inability to produce and } \\
\text { disseminate highly relevant products, } \\
\text { productions tailored to a general rather } \\
\text { than expert audience, limited access to } \\
\text { online or even paper sources (e.g. } \\
\text { scientific journals, databases and even } \\
\text { grey literature), limited capacity to assess } \\
\text { research findings, limited resources to } \\
\text { scale up research-related activities, no } \\
\text { dedicated position for knowledge } \\
\text { translation, very limited partnerships with } \\
\text { the local and sub-regional research } \\
\text { structures for access to researchers and } \\
\text { experts for capacity strengthening and no } \\
\text { dedicated resources to develop and } \\
\text { provide tools (e.g. evidence-based } \\
\text { guidelines, fact sheets and position } \\
\text { statements). } \\
\text { Facilitators: establishing linkages and } \\
\text { having regular contact with potential } \\
\text { users of research findings. }\end{array}$ \\
\hline $\begin{array}{l}\text { Hyder et al. } \\
\text { (2011) }\end{array}$ & $\begin{array}{l}\text { To understand the perspectives and } \\
\text { attitudes of policymakers towards the } \\
\text { use and impact of research in the } \\
\text { health sector in low- and middle- } \\
\text { income countries }\end{array}$ & $\begin{array}{l}\text { Qualitative study } \\
83 \text { semi-structured in-depth interviews } \\
\text { with purposively selected policymakers. }\end{array}$ & Malawi & $\begin{array}{l}\text { Barriers: poor packaging of research } \\
\text { findings; poor dissemination of research } \\
\text { findings, absence of personal contact, lack } \\
\text { of timeliness, lack of relevance of } \\
\text { research results, lack of mutual trust, } \\
\text { power and budget struggles and limited } \\
\text { capacity in-country. } \\
\text { Facilitators: establishing a systemic } \\
\text { approach to feeding research results to } \\
\text { policymakers that did not rely on the } \\
\text { personal preferences of researchers and } \\
\text { promoting dialogue between } \\
\text { policymakers and researchers. }\end{array}$ \\
\hline
\end{tabular}

were iteratively updated as new factors were identified. Additional themes that emerged during data analysis were refined. Both recurring and additional themes were categorized. Some themes were modified and merged, for example, 'contact and relationships was modified to 'contact and collaboration' and 'policy' and 'policymaker' characteristics were merged to 'policy and policymaker' characteristics.

Oliver et al. provided a summary of barriers and facilitators, but we opted to provide themes instead because there were many emerging factors which would have resulted in very long lists in Table 2 . The process included sharing analyzed data with other team members to confirm or challenge the emerging themes and to provide feedback to the lead researcher for the further refinement of the themes. One of the researchers played a critical reader role to assist with refinement of the emerging themes. Although it was evident that there was an overlap across categories, some barriers and facilitators were categorized based on the level at which they primarily function and might be most 


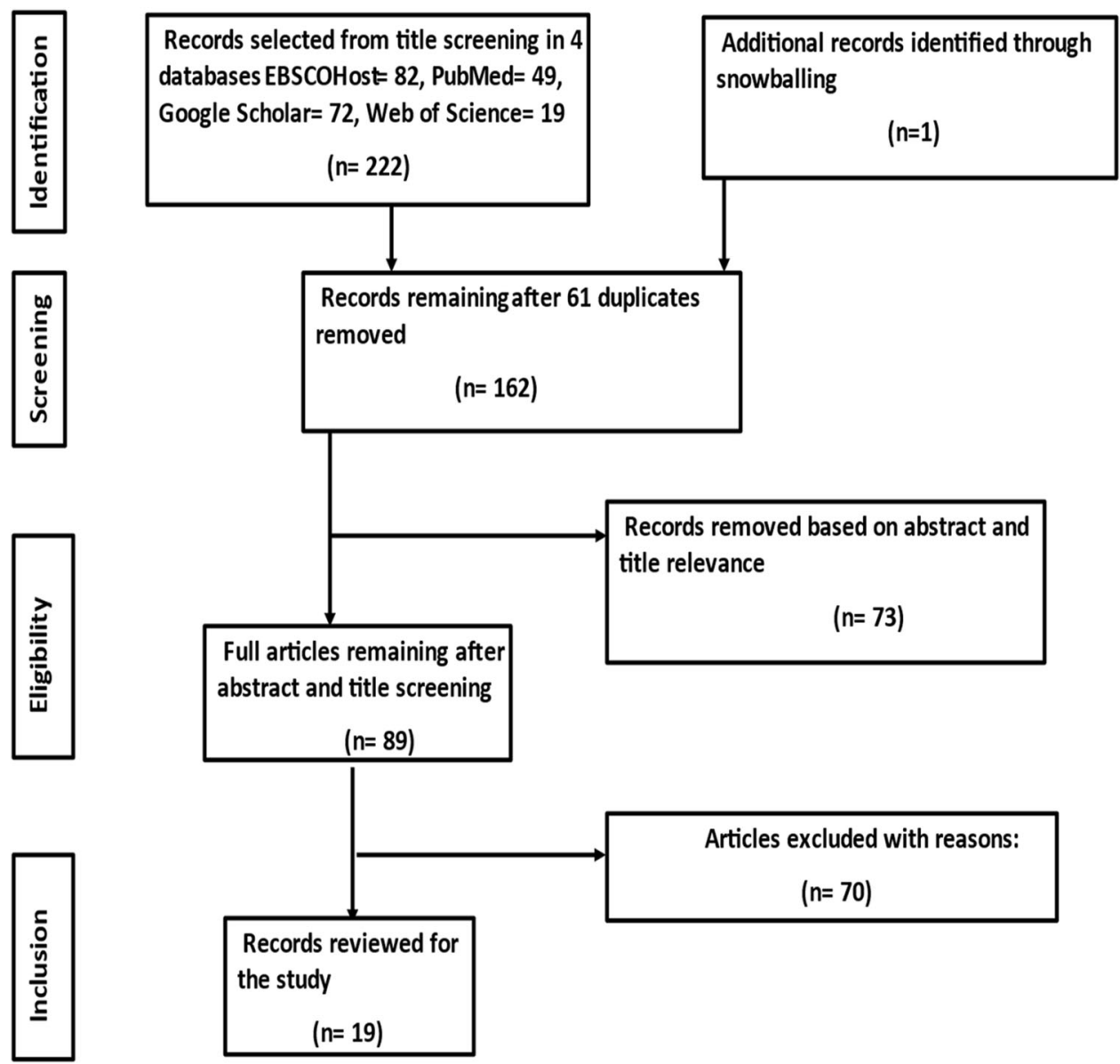

Fig. 1 Flowchart of study selection process. PRISMA flow diagram. A diagram of the number of records identified, included and excluded in the article.

appropriately addressed. The extracted information was grouped into five themes namely: organizations and resources, contact and collaboration, research and researcher, policy and policymaker and government characteristics. Preliminary results were shared at a Doctoral seminar which was also attended by research experts for input and further refinement of themes.

\section{Results}

Overview of selected studies. We reviewed 19 studies from an initial collection of 223 articles from PubMed, Google Scholar, Web of Science, EBSCOhost and an additional article added from snowballing (Fig. 1). The studies reviewed dealt with barriers and facilitators of translation of research into policy and were conducted in 16 SSA countries representing East Africa (5), Southern Africa (4), West Africa (3) Central Africa (3) and North Africa (1): Botswana, Burkina Faso, Cameroon, Central African Republic, Democratic Republic of Congo, Ethiopia, Ghana, Kenya, Malawi, Mozambique, Nigeria, Rwanda, South Africa, Sudan, Uganda and Zambia. Most of the studies $(n=11)$ were done in single countries (Ezenwaka et al., 2020, Uneke et al., 2017, Mwendera et al., 2016, Ssengooba et al., 2011; Young et al., 2018, Nabyonga-Orem et al., 2014a, 2014b; Mapulanga et al., 2019; Inguane et al., 2020; Cockcroft et al., 2014; Hamel and Schrecker, 2011; Hyder et al., 2011) whilst eight were done in multicountries (El-Jardali et al., 2014; Kalbarczyk et al., 2021; Kumar et al., 2020; Oronje et al., 2019; Naude et al., 2015; Schleiff et al., 2020; Shroff et al., 2015). Although all the studies were done in SSA countries and addressed the barriers and facilitators of evidence-informed policymaking identified there, only five were done by authors based in Africa with most of them (11) having been conducted by a mix of authors based in Africa and elsewhere; and three having been exclusively done by authors not based in Africa.

Six studies looked at evidence-informed policymaking in general whilst two dealt with maternal, new-born, child health and nutrition, one was about endemic tropical diseases, one dealt with community health policy and financing, two with malaria policy, one with user fees abolition, three with building capacities of decision-makers in evidence-informed decision-making and another three with knowledge translation platforms/activities. Of the 19 articles reviewed, 11 were qualitative, six were mixed and two were quantitative studies. There was a gradual increase in articles addressing barriers and facilitators of translating research into policy in sub-Saharan Africa between 2010-2016 and 2019-2020 with most of the articles reviewed having been published in 2014 and 2020. All the studies $(n=19)$ focused on both barriers and facilitators of translating research into policy. Most of the reviewed studies were conducted in Nigeria with four studies and Malawi with five studies indicating that those two countries had more studies that highlighted barriers and facilitators. The findings indicate that SSA made greater effort to improve promotion of use of research evidence in policymaking with most of the countries having at least three or more articles each on barriers and facilitators of translating research into policy.

Summary of key barriers and facilitators of translating research into policy. The most frequently reported barriers were lack of capacity by policymakers to assess, adopt, and use evidence for policy decisions, inaccessibility of research evidence, 
Table 2 Summary of identified barriers and facilitators.

\section{Barriers}

Organisations and resource barriers: inability to produce and disseminate highly relevant products; no written policy that mandates staff to base their work on evidence; inadequate numbers of staff; poor functionality of research units and research ethics committees; productions tailored to a general rather than an expert audience; limited access to online or even paper sources like scientific journals, databases and even grey literature limited resources to scale up research-related activities; no dedicated position for knowledge translation; no systematic way/mechanism for use of research in maternal, new-born and child health $(\mathrm{MNCH})$ intervention, very limited partnerships with the local and sub-regional research structures for access to researchers and experts for capacity strengthening; no dedicated resources to develop and provide tools (e.g. evidence-based guidelines, fact sheets and position statements); lack of skilled human resources to conduct EIHP activities; high turnover in top level policymakers in the government; difficulty in managing multiple roles within the KTPs; weak capacity to undertake health policy and systems research; research questions framing guided by academic interests and funders' focus without recourse to the decision-makers; moribund research units of the Department of Planning and Statistics within the State Ministry of Health; lack of funds; weak Health Management and Information Systems; lack of participation of non-health actors; limited decision space of users of evidence; inadequate capacity for organizations to conduct policy-relevant research (weakness in the capacity of $\mathrm{MOH}$ to lead evidence generation, synthesis and application); inadequate budgetary allocation for policy-relevant research; poor dissemination of research evidence to policymakers; lack of platforms for researcher-public engagement; unknown WHO policy position; lack of malaria research repositories; lack of training on database use; dysfunctionality of databases; language barriers or lack of communication processes within and between $\mathrm{MOH}$ and other institutions and practices; prioritizing global agencies instead of national ones; treating national level stakeholders as secondary audiences; unavailability of research when it is required; challenges procuring internal and external resources to conduct knowledge translation; poor packaging of research results; poor planning for policy change; gaps in service delivery; lack of health system capacity to implement new policy; influence of drug companies; lack of financial sustainability; a top-down approach to decision-making; lack of participation of non-health actors; lack of research staff for Parliament; lack of recognition (e.g. incentives or rewards) for successfully conducting knowledge translation; donor-driven research priorities and inaccessibility of research evidence.

Contact and collaboration barriers: weak institutional linkages between producers and users of evidence; poor participation of non-health actors lack of interaction fora for researchers and policymakers and absence of personal contact.

Poor collaboration and networking between researchers and policymakers

Research and researcher barriers: lag or lack of local research production (gaps in research production); lack of high-quality usable evidence; available evidence not generalizable; limited relevant evidence; researchers' lack of communication skills; lack of researcher collaboration; funder-driven research; research evidence not considered the main driver of policy decisions; research evidence frequently perceived as not available; research ill-timed, research not applicable or not well aligned with health services; contradictory research evidence;

\section{Facilitators}

Organizations and resource facilitators: strong leadership and support from policymakers at the government level; support provided to KTPs by policymakers and international funders; institutional investments in capacity strengthening among research users to acquire, adapt and apply research; improved individual competence and organizational capacity for EIDM; increasing interest to integrate research evidence in decision-making processes among users and producers of evidence; active engagement of decision-makers in the Ministry of Economic Planning and Budgeting to facilitate the release of budgetary allocations to health; availability of donors/partners; increase in relevance of evidence; increased capacity for evidence use; support mechanisms like training mentorship activities and programs for researchers, policymakers and media practitioners; availability of platforms and structures in $\mathrm{MOH}$ to discuss evidence; introducing a budget line for the Research and Development unit to facilitate evidence use; adequate and widespread dissemination of research findings to relevant stakeholders; establishment of a Policy Development Unit (PDU); establishment of knowledge translation platforms (KTP); establishment of Knowledge Translation Units (KTU); availability of the National Health Research Agenda; availability of local research results; availability of diverse local researchers and stakeholders supporting knowledge translation; establishment of a technical working group to discuss research; establishment of a division of Research and Development to support $\mathrm{MOH}^{\prime} \mathrm{s}$ use of research evidence; annual research dissemination conferences; appropriate packaging of research results; having a repository with evidence summaries, policy briefs that are in policymakers' areas of interest; incentivizing staff; aligning government policies with international declarations and goals; access to real-time data as well as share data across different agencies and partners; evolution of agencies to take operations research; use of social networks and media; raising the public profile of key experts and support them to undertake media relations work; availability of high-quality local evidence; provision of guidelines, medicines and training for health workers on the new policy; establishing a designated unit within a $\mathrm{MOH}$ or across multiple sectors of government and having ongoing, structured and accountable contact between civil servants (CSs), researchers and a range of other stakeholders; capacity strengthening and engagement of CSs; introduction of a budget line by Kenya $\mathrm{MOH}$ for the Research and Development unit to facilitate evidence use in the ministry; revival of the research unit in the Department of Planning Research and Statistics (PRS), access to electronic-based routine health information systems (HIS) data; logistical support and international non-governmental organizations (NGOs) funding.

Contact and collaboration facilitators: Establishing linkages and having regular contact with potential users of research findings; diverse stakeholder engagement; existing relationships and linkages with Health Policy Research Group; willingness to create a knowledge translation forum between users and producers of evidence; collaboration and networking between researchers and policymakers; establishing a designated research unit with $\mathrm{MOH}$ or across multiple sectors of government and having ongoing; structured and accountable contact between civil society, researchers and a range of stakeholders; shared platforms for learning and decision-making; cultivation of coalitions and inter-institutional linkages to increase joint and shared learning with key institutions that influence health decision-making; communication and team building strategies; individual and institutional relationships with policymakers; collaborative decision-making at health sector regular meetings; promoting dialogue between policymakers and researchers and establishment of an annual forum for presentation and consideration of research results for possible adoption and incorporation into policymaking process.

Research and researcher facilitators: Facilitators identified under this theme included improved data quality; involving policymakers in research design and execution; a research issue that generates sufficient interest in both the research and policymaking communities (relevance of evidence); clear understanding of expected outcomes; timeliness of evidence; availability of competent in-country researchers; consistent results from multiple studies performed by different researchers; evidence generated by credible international researchers/regional networks and consensus on research 


\section{Table 2 (continued)}

\section{Barriers}

poor research dissemination skills; researchers' lack of technical capacity in policy processes; researchers' lack of diverse political influences which drive policy formulation or policy change; lack of data needed for each step of the policy processes; untimely dissemination of research results; lack of knowledge about knowledge translation and its processes; lack of skills to conduct knowledge translation activities; and use of jargon.

Policy and policymaker barriers: Limited capacity to acquire, assess, adapt and use research evidence for policy decisions, resistance to change

(from implementers); poor demand and support for research evidence; policymakers' indifference to research evidence; cultural values;

discomfort with complex messages; policymakers' lack of time to find and read research articles; use of policy briefs alone and the sustainability of new policy.

Government barriers: political influences; limited funding of research by the government; political interference and nepotism, political feasibility and power and budget struggles

\section{Facilitators}

results; soft skills to navigate the policy process and engage with policymakers; researchers' need to understand the limitations of their evidence and establishing a systematic approach to feeding research results to policymakers that do not rely on personal preferences of researchers.

Policy and policymaker facilitators: Use of policy briefs; policies to ensure that any newly introduced policy must be accompanied with evidence; policymakers who are familiar with EIDM; willingness of policymakers to enhance skills in EIDM; policymakers flagging priority research areas; involving top-level policymakers in the selection of technical staff to be trained on the use of evidence; an interested and informed group of policymakers; willingness of $\mathrm{MOH}$ to use evidence; allowing policymakers' needs to drive research and a culture of $\mathrm{MOH}$ using evidence.

Government facilitators: good political will; improved funding for policy relevant research; minimization of political influence; establishment of a division of Research and Development to support $\mathrm{MOHs}$ use of evidence (the institutionalization of the use of health research evidence) and aligning government policies with international declarations and goals. lack of repositories for research findings, policymakers' lack of time to find and read research articles, lack of high-quality usable evidence and limited funding for research. The key facilitators to the utilization of research evidence into policy include increased capacity for evidence use, involving policymakers in research design and execution, availability of high-quality usable evidence, constant collaboration between researchers and policymakers, support mechanisms like training mentorship activities and programmes for researchers, policymakers and media practitioners, use of policy briefs, appropriate packaging of research results, repositories with evidence summaries in the policymakers' area of interest, proper dissemination of research findings, diverse stakeholder engagements, increase in funding for research and the establishment of departments of research in the $\mathrm{MOH}$.

Five themes of barriers and facilitators were identified from all the 19 papers: (1) organizations and resources, (2) contact and collaboration, (3) research and researcher, (4) policy and policymaker and (5) government. A total of 74 barriers were identified and thematically classified as follows: 40 under organizations and resources, 4 under contact and collaboration, 18 under research and researcher, 8 under policy and policymaker and 4 under government. A total of 65 facilitators were identified in the study. Thirty-three (33) facilitators were under organizations and resources, ten under contact and collaboration, nine under research and researcher, eight under policy and policymaker and five under government.

Barriers to research translation into policy. Of the 19 reviewed articles that addressed barriers, 1 article (Hyder et al., 2011) addressed all five themes. Six articles (El-Jardali et al., 2014; Ezenwaka et al., 2020; Kumar et al., 2020; Oronje et al., 2019; Mwendera et al., 2016; Ssengooba et al., 2011) addressed four themes. Five articles (Uneke et al., 2017; Naude et al., 2015; Young et al., 2018; Inguane et al., 2020; Kalbarczyk et al., 2021) addressed three themes. Six articles (Nabyonga-Orem et al., 2014b; Shroff et al., 2015; Nabyonga-Orem et al., 2014a; Mapulanga et al., 2019; Cockcroft et al., 2014; Hamel and Schrecker, 2011) addressed two themes. One article (Schleiff et al., 2020) addressed one theme. None of the themes was dominant in all the articles. The theme of organizations and resources was present in 18 articles (El-Jardali et al., 2014; Ezenwaka et al., 2020; Kumar et al., 2020; Oronje et al., 2019; Uneke et al., 2017; Mwendera et al., 2016; Schleiff et al., 2020; Ssengooba et al., 2011; Young et al., 2018; Nabyonga-Orem et al., 2014b; Shroff et al., 2015; Nabyonga-Orem et al., 2014a; Mapulanga et al., 2019; Inguane et al., 2020; Cockcroft et al., 2014; Hamel and Schrecker, 2011; Hyder et al., 2011; Kalbarczyk et al., 2021). The theme of policy and policymaker was addressed by 14 articles (El-Jardali et al., 2014; Ezenwaka et al., 2020; Kumar et al., 2020; Oronje et al., 2019; Uneke et al., 2017; Mwendera et al., 2016; Naude et al., 2015; Ssengooba et al., 2011; Young et al., 2018; Shroff et al., 2015; Nabyonga-Orem et al., 2014a; Hamel and Schrecker, 2011; Hyder et al., 2011; Kalbarczyk et al., 2021). The theme of research and researcher was addressed in 12 articles (El-Jardali et al., 2014; Kumar et al., 2020; Mwendera et al., 2016; Naude et al., 2015; Ssengooba et al., 2011; Young et al., 2018; Nabyonga-Orem et al., 2014b; Shroff et al., 2015; Mapulanga et al., 2019; Inguane et al., 2020; Cockcroft et al., 2014; Hyder et al., 2011; Kalbarczyk et al., 2021). Theme of contact and collaboration was present in three articles (Ezenwaka et al., 2020; Oronje et al., 2019; Uneke et al., 2017). The theme of government was present in nine articles (ElJardali et al., 2014; Ezenwaka et al., 2020; Kumar et al., 2020; Oronje et al., 2019; Mwendera et al., 2016; Naude et al., 2015; Ssengooba et al., 2011; Inguane et al., 2020; Hyder et al., 2011). The theme of organizations and resources was the most reported on constituting $94 \%$ of the articles. Of the five themes, the most frequently reported on themes were organizations and resources, policy and policymaker and research and researcher themes.

Facilitators of research translation into policy. Even though all the 19 reviewed articles addressed facilitators, none of them addressed all the five themes. One article (Shroff et al., 2015) addressed four themes. Seven articles (El-Jardali et al., 2014; Ezenwaka et al., 2020; Uneke et al., 2017; Mwendera et al., 2016; Schleiff et al., 2020; Ssengooba et al., 2011; Nabyonga-Orem et al., 2014a; Kalbarczyk et al., 2021) addressed three themes. Five articles (Kumar et al., 2020; Oronje et al., 2019; Schleiff et al., 2020; Inguane et al., 2020; Hyder et al., 2011) addressed two themes. Six articles (Naude et al., 2015; Young et al., 2018; Nabyonga-Orem et al., 2014b; Mapulanga et al., 2019; Cockcroft et al., 2014; Hamel and Schrecker, 2011) addressed one theme. The theme of organizations and resources was addressed in 14 articles (El-Jardali et al., 2014; Ezenwaka et al., 2020; Kumar et al. 2020; Oronje et al., 2019; Uneke et al., 2017; Mwendera et al., 2016; Schleiff et al., 2020; Ssengooba et al., 2011; Shroff et al., 2015; Nabyonga-Orem et al., 2014a; Mapulanga et al., 2019; 
Inguane et al., 2020; Cockcroft et al., 2014; Kalbarczyk et al., 2021). The theme of contact and collaboration was present in 13 articles (El-Jardali et al., 2014; Ezenwaka et al., 2020; Oronje et al., 2019; Uneke et al., 2017; Mwendera et al., 2016; Schleiff et al., 2020; Ssengooba et al., 2011; Young et al., 2018; Shroff et al., 2015; Inguane et al., 2020; Hamel and Schrecker, 2011; Hyder et al., 2011; Kalbarczyk et al., 2021). Seven articles (Kumar et al., 2020; Uneke et al., 2017; Ssengooba et al., 2011; Shroff et al., 2015; Nabyonga-Orem et al., 2014a; Hyder et al., 2011; Kalbarczyk et al., 2021) addressed the theme of research and researcher facilitators. Policy and policymaker theme was present in five articles (El-Jardali et al., 2014; Uneke et al., 2017; Naude et al., 2015; Shroff et al., 2015; Nabyonga-Orem et al., 2014a). The theme of government was addressed in five articles (Ezenwaka et al., 2020; Oronje et al., 2019; Mwendera et al., 2016; Schleiff et al., 2020; Nabyonga-Orem et al., 2014b). The themes of organizations and resources and contact and collaboration were the most reported on constituting 72 and $66 \%$ respectively.

\section{Discussion}

The study aimed to identify barriers and facilitators of research translation into policy in SSA countries with a view to improve translation of health research findings into policy. A gradual increase in articles addressing barriers and facilitators of translating research into policy in sub-Saharan Africa was observed for the period 2010-2016 and 2019-2020 with most of the articles published between 2014 and 2020. Although the subject of evidence-informed policymaking has gained global attention, SSA countries still face major challenges in their effort to translate research findings into policy. Evidence-informed policymaking will only be possible when barriers are pragmatically addressed and facilitators which are likely to affect research uptake are utilized (Mwendera et al., 2016). Overall, the present study lends support to previous findings in the literature indicating that numerous barriers are common across settings in low- and middle-income countries. There are similarities in the barriers and facilitators among the countries. Our findings are consistent with those of Ellen et al. and Oliver et al. who reported similar barriers and facilitators (Ellen et al., 2016; Oliver et al., 2014). Organization and resources theme barriers were the most reported on both barriers and facilitators suggesting that effort was made to address barriers and facilitators in this category. Our findings lend ongoing support to the importance of organizational factors as facilitators and/or barriers of evidence-based policymaking within an organization.

The main barrier consistently highlighted as limiting the translation of research into policy was the lack of capacity by policymakers to synthesize, adopt and translate evidence for policy decisions. Policymakers play a critical role in the translation of research findings into policy but may not be appropriately equipped for the task (Mwendera et al., 2016; Hyder et al., 2011). The limited capacity of policymakers to use evidence has resulted in delayed adoption of research findings for policy formulation. A participant in one of the studies reviewed lamented that policymakers rely more on recommendations from World Health Organization (WHO) with little consideration of local evidence (Mwendera et al., 2016). When WHO does not have an established policy position on the issue at hand, policymakers become reluctant to use evidence for policy formulation. It therefore seems that evidence translates slowly in SSA countries since policy is driven by guidance from international agencies. Policymakers lack the capacity to effectively translate international and national health policy recommendations to local context (Uneke et al., 2015a).
The theme of research and researcher had more barriers than facilitators. Lack of relevant evidence was a prominent barrier in the reviewed articles. Similar findings by Holdsworth et al., Verstraeten et al. and Morris et al. indicate that existing research evidence may not adequately address the priorities of national and local contexts and particularly the needs of low- and middleincome countries (Holdsworth et al., 2015; Verstraeten et al., 2012; Morris et al., 2008). Lack of relevant research evidence during policy dialogues generally results in the use of anecdotal evidence resulting in ineffective interventions being implemented (Araujo De Carvalho et al., 2014). In many African countries the production of research evidence is limited due to lack of funding for research (Ezenwaka et al., 2020; Oronje et al., 2019; Uneke et al., 2017). Yimgang et al. also observed that there is limited funding to support evidence generation and allowances for stakeholders attending policy dialogues (Yimgang et al., 2021).

Researchers' influence on policy is shaped by their independence to provide credible research and agility to navigate the local policy landscape and to participate in policy debates (De Sardan, 2011). Independence to produce relevant research is closely linked to financial sustainability. Due to limited funding, researchers often get involved in consultancy work which requires commissioned reports leaving them with little time to conduct relevant research (De Sardan, 2011). In consultancies, researchers have limited input in the design and execution of research and the development of policies (Grobbelaar and Harber, 2016). Again, when funding is limited, researchers opt for funder- driven research which addresses funder priorities. Health research priorities in one-third of African institutions are determined by agencies based outside the host country and less than one-fifth of African countries have guidelines on development of collaborative agreements on health research involving institutions outside the country (Uthman et al., 2015). Without such guidance documents, health research in the African continent will probably be influenced more by the demands of foreign institutions than by health priorities of the host country.

Consequently the research results are rarely used for policy formulation because policymakers are skeptical about research funded by donors because of the possibility of conflict of interest (Nabyonga-Orem et al., 2014a). An example of such situations is highlighted in a study conducted in Ghana where the donors' interests took priority over the policy agenda (Burris et al., 2011). Politics also play a role in decision-making. In SA, politicians like Premiers (Provincial Leaders) and Ministers may be receptive to using evidence that they understand, while other role players, for example the industry, sometimes lobby strongly to block evidence-based policy decisions that can negatively affect their profitability (Naude et al., 2015). Evidence coming from a local source is often given preference by decision-makers (particularly in LMICs), as is evidence originating from a setting similar to the user's (Witter et al., 2019), or resulting from research commissioned by the user (Haynes et al., 2018). Evidence gained through trusted relationships (Dobbins et al., 2009; Malla et al., 2018), and communicated in ways preferred by decision-makers and other users (Haynes et al., 2018; Witter et al., 2019) also facilitates uptake.

Lack of funding for journal publication is a barrier to translation of research into policy. Unfortunately, most LMIC researchers cannot afford to publish in open-access journals and hence their work is not widely read. Even though some adjustments such as waiver of publishing fees have been made for researchers from countries which were classified by the World Bank as low-income or lower-middle-income economies as of September 2013 and which have a funding gross domestic product (GDP) of less than 200 billion US dollars the page fees are 
still high for sub-Saharan countries (Tzarnas and Tzarnas, 2015). Researchers' reluctancy to publish in local journals where research evidence may be more accessible to policymakers is another barrier to translating research into policy (Lee and Simon, 2018). In South Africa, researchers face challenges in the dissemination and visibility of their research (Czerniewicz and Goodier, 2014). The analyses of publication input and citation impact of about 200 South African journals showed that a vast majority of local journals were virtually invisible within the global science arena (Tijssen et al., 2006). In a study conducted in 2013, a Google search of South African research in an area where it was known that much research had been undertaken showed that the research was invisible (Czerniewicz and Wiens, 2013). Even though the Department of Higher Education and Training (DHET) does not differentiate between national and international publications, some universities offer larger rewards for articles in internationally published journals than local journals resulting in South African researchers preferring to publish in international journals (Lee and Simon, 2018).

In Africa there continues to be little investment for research due to lack of funding. In 2011, when worldwide expenditure on research was $1.77 \%$ of the total global gross domestic product (GDP), Kenya and South Africa spent $0.1 \%$ and $0.76 \%$ of their GDP on research, respectively (Kumwenda et al., 2017). Heeding to the call made by the United Nations on Sustainable Development Goals (SDG) to promote research in all fields and for full research capacity in all countries by 2030, African leaders committed to reserving a certain GDP \% for research and development (R\&D). Only South Africa currently seriously supports its own research. Research capacity in South Africa is more developed than in other African countries (Kumwenda et al., 2017). South Africa dominates the health research publications in the WHO African region because there is an increasing realization of the need to promote indigenous health research in the country (Senkubuge and Mayosi, 2012). Following the end of apartheid in 1994, considerable policy-level steps were taken to reorient health research towards the needs of most of the population. Even though South Africa is at the top in terms of health research production, the health research system is severely underfunded from local sources. The National Department of Health spent only $0.37 \%$ (416.5 million Rands) of its health budget of 112.6 billion Rands in health research in the 2010/2011 financial year which fell short of the recommendations of the health research policy of 2001 and the subsequent undertakings at the Mexico Ministerial Forum on Research for health and the Global Ministerial Forum on Research for Health in Bamako (Organization, 2005).

Despite the availability of research evidence, policymakers sometimes do not use the evidence because of their personal beliefs, cultural values, and concerns regarding the impact of new interventions. For example, in Uganda the safe male circumcision policy process was delayed because political opposition leaders were concerned about feasibility of the intervention and the unintended harmful impact of such a policy on the community as the public might misinterpret the intention of such interventions (Ssengooba et al., 2011).

The inaccessibility of research evidence was also frequently reported as a barrier. Research remains inaccessible to policymakers mainly because it is packaged and disseminated in formats that policymakers find difficult to use. This is consistent with Aryeetey et al. who in their analysis of barriers towards sustainable nutrition research stated that "although not limited to Africa, it is known that many nutrition studies remain inaccessible to most policymakers largely because of the ways in which they are packaged and disseminated to policymakers" (Aryeetey et al., 2017). They further stated that a significant proportion of local research in Africa is published in African-based journals or shared as grey literature but is not visible to policymakers and therefore difficult to access. In SSA countries there is a problem of lack of repositories for research findings (Mwendera et al., 2016) with most of the reports scattered across institutions or ethical approval bodies which makes it difficult for policymakers to access. The situation is made worse by academic researchers who choose to publish in high-impact journals that may not be easily accessible to policymakers in LMICs (Shroff et al., 2017; Meisel et al., 2016).

Researchers do not always make effort to share their research findings with relevant policymakers locally preferring to disseminate their findings externally and publishing in international journals that are not easily accessible to local policymakers. A study participant in Mwendera et al. commented that "it is only when one attends international conferences that they get to know about research done in and about their country" (Mwendera et al., 2016). Even though research evidence is made accessible through local journals, policymakers do not usually read journal articles because they do not have the time for that (Hyder et al., 2011). Furthermore, policymakers find peer-reviewed journals very daunting and taxing to read and more often they do not find the information they need (Kite et al., 2015). However, it is important to remember that simply increasing access to research findings, and supply of information to policymakers will not automatically lead to "better decisions" (Evans et al., 2017). Presenting research findings in less complex formats, such as policy briefs, research summaries and infographics has been shown to improve research uptake by policymakers (Shroff et al., 2017; Newman, 2014).

Organizational and resources facilitators such as increased capacity for evidence use, involving policymakers in research design and execution and availability of high-quality usable evidence emerged from this study as important factors for improving translation of research findings into policy. Similar results have been reported by Oliver et al. (Oliver et al., 2014). Uneke et al. in their study on improving maternal health and child health stated that capacity strengthening is a major factor with potential to boost the interest in the transfer and uptake of research evidence into policy and practice (Uneke et al., 2017). Capacity strengthening instills a culture of using evidence for decision-making. There are many techniques that can be utilized to enhance the capacity of policymakers. These include collaboration between researchers and policymakers, skills training workshops, mentoring, hosting and facilitating networks and knowledge services and participating in and supporting relevant research (Deans and Ademokun, 2015). The most effective facilitator for increasing capacity for policymakers is constant collaboration between researchers and policymakers (Yimgang et al., 2021; Young et al., 2018; Oliver et al., 2014). Collaboration between researchers and policymakers facilitates the participation of researchers in the policy process beneficial to policymakers because capacity strengthening activities could be developed to improve their skills regarding evidence-based policymaking processes (Berman et al., 2015). This finding highlights the need to develop knowledge translation platforms that encourage the involvement of all key stakeholders in the entire process of health policymaking.

Young and colleagues reported that researchers were paired with policymakers to increase the uptake of evidence in health policy decisions; researchers helped with clarifying research questions, appraising systematic reviews, preparing short evidence summaries and providing feedback to policymakers (Young et al., 2018). WHO stresses the value of closer collaboration between research organizations and the policymakers for evidence creation to be aligned with policy priorities 
(Organization, 2016). Co-designing of research with policymakers and involving them during implementation was frequently mentioned in reviewed articles (Ezenwaka et al., 2020; Uneke et al., 2017). It is believed that long-term, continuous contact between researchers and knowledge users may help sustain local commitment to implementation of study recommendations (Malla et al., 2018). If policymakers are involved from conceptualization of the study to execution, they will have confidence in the research findings and that may increase acceptability and enhance translation of the research evidence into policy (Chu et al., 2014). This will also assist researchers in understanding the policymaking process and on the other hand policymakers will be kept aware of the research in progress. Ogbe et al. in their study on sexual reproductive health suggested that developing strong communication pathways, skills and practices with policymakers sustained over time, was essential for effective translation and dissemination of sexual and reproductive health $(\mathrm{SRH})$ research evidence (Ogbe et al., 2018).

Understanding the decision-making process and the information sources that are most valued by policymakers can strengthen researchers' efforts to engage and advocate for specific health research priorities (Oliver et al., 2014). Training will increase the awareness of policymakers and technical knowledge on utilization of research findings in the policymaking process. This is supported by Uneke et al. who opined that it is a well- established fact that skills training could help policymakers and their aides, not only to identify research evidence that has policy relevance, but also distinguish research of high and low methodological quality (Uneke et al., 2015b). Mentoring will guide policymakers in the identification of policy options and subjection of these options to evidence synthesis. It can also be used to provide technical guidance to policymakers to enable them to produce policy briefs. Uneke and colleagues described a mentorship program that was organized to strengthen capacity of policymakers in developing policy briefs; policymakers drafted policy briefs on the control of infectious diseases of poverty with technical support and mentorship of researchers (Uneke et al., 2015b).

Availability of relevant research is crucial to the formulation of health policies. If research findings are relevant and made available especially in the local context they are able to influence policy (Mwendera et al., 2017). Malawi and Tanzania are examples where research was instrumental in changing the WHO intermittent preventive treatment of malaria during pregnancy with sulfadoxine-pyrimethamine (IPTp-SP). A new policy of administering IPTp-SP at each antenatal visit with the first dose given as early as possible in the second trimester and the following doses given at monthly intervals up to the time of delivery was adopted (Mwendera et al., 2016; Mubyazi and Gonzalez-Block, 2005). In South Africa, Mozambique and Zimbabwe research also contributed in shaping policies around eclampsia and malaria control (Woelk et al., 2009).

The use of policy briefs has been mentioned in the reviewed articles as an important policy tool that is increasingly being used to facilitate the use of evidence in policymaking. Policy briefs are an example of knowledge sharing tools that can encourage policymakers to receive research evidence and use it. In a study on information-packaging efforts to support evidence-informed policymaking in LMICs, Adam et al. observed that the importance of developing concise materials and tools to communicate various types of information to policymakers is increasingly gaining recognition (Adam et al., 2014). There are now several journals that specialize on policy briefs. Research funders can support the development of policy briefs by making it mandatory for researchers to produce policy briefs out of their work as a way of ensuring that research findings are presented in a format that policymakers can read and easily understand. It is recommended that postgraduates that are doing policy related work be trained on how to write policy briefs so that they can disseminate their findings smoothly. Universities could include policy brief writing in the curriculum and run workshops on translation of research findings targeting final year $\mathrm{PhD}$ students. In addition to training postgraduates in policy briefs writing, it may also be important for researchers who are not trained in policy briefs writing or development to work with colleagues who have the skill. This would facilitate the translation of research findings into actionable interventions or measures. In other schools or departments within the university, there might be people who are specialized in policy briefs writing who may be able to assist them to write for policymakers.

Policy briefs are excellent policy working tools that enable policymakers and other stakeholders in the health sector to interact and share knowledge and adapt effective strategies for improving health (Abekah-Nkrumah et al., 2018). However, Shroff et al warned that using policy briefs alone without the use of other factors and interventions did not make much difference in enabling the incorporation of research into policy and practice (Shroff et al., 2015). Use of policy briefs can be aided by having repositories with evidence summaries in the area of interest of policymakers (Naude et al., 2015). Quite often policymakers are invited to open or close conferences and made to read technical speeches. Researchers ought to use such opening and closing opportunities to hand over policy briefs to the policymakers. When a researcher writes a policy brief and gives it to the policymaker, the policymaker should not implement it without involving other relevant stakeholders and community members to voice their opinions/concerns and make recommendations.

Policymakers should assess the quality and contents of the policy brief and if necessary, add or introduce relevant evidence not included in the researcher's version and ensure that the policy brief is considered for use in the development of a policy. The policymaker should also involve the researcher in the dialogue to clarify judgements made in the policy brief as well as ensuring that the contents of the policy brief are clear to other stakeholders. However, it is well accepted that researchers have the obligation to disseminate findings of their research to the public, though it may not be through policy briefs. There may be other ways such as stakeholder feedback sessions, annual research dissemination conferences, publication in local journals, community feedback meetings, social media (Twitter, LinkedIn, Facebook, Research Gate, blogs), news media (press releases, radio, and newspapers) and informal one-on-one meetings. These platforms can also be used to discuss and distribute policy briefs.

Diverse stakeholder engagements may lead to new research questions that address national priorities, result in policy shifts and build relationships (Kalbarczyk et al., 2021). Stakeholder feedback meetings may also increase researchers' access to policymakers. Such meetings may also increase the relevancy and credibility of the research produced and the chances of its uptake in policy and practice (Boaz et al., 2018; Goodman and Sanders Thompson, 2017). It is important to encourage policymakers to attend such stakeholder feedback meetings since those are platforms that researchers can use to convince policymakers that the findings will positively contribute to policy. Unfortunately, this still tends to be inadequate as researchers make little effort to have stakeholder feedback sessions and to attend annual dissemination conferences. Researchers can also use stakeholder feedback meetings to highlight implications of their research on policy.

Governments can support high quality research production through increasing funding allocated to health research and through investing and supporting capacity building of researchers (El-Jardali et al., 2018). Governments can also support the 
production of evidence-driven high-quality research and facilitate use of evidence for policy by establishing the departments of Research and Development in the MOH. In 2013, the Kenyan government restructured the $\mathrm{MOH}$ and established, for the first time, a division of Research and Development and introduced a budget line for the Research and Development Unit to promote and support MOH's use of research evidence (Oronje et al., 2019). In Malawi, the government established the Department of Research in $\mathrm{MOH}$ and in 2012 revived a Policy Development Unit (PDU) with the aim of driving evidence-driven research (Mwendera et al., 2016). This way the governments' research needs will guide the generation of research aligned with national agendas and researchers will support the process by conducting research that collaborates with MOH needs (Schleiff et al., 2020). Researchers can also work to produce policy-relevant research which will ensure that limited resources are properly coordinated and used. Funders must ensure that policy aspects are addressed in projects they fund to avoid having research outputs that are just academic. There is also a need to strengthen research capacity in LMIC countries (Bowsher et al., 2019; Tagoe et al., 2019; Franzen et al., 2017).

\section{Limitations}

Our findings should be considered in the context of some study limitations. The number of papers we reviewed was relatively small and generalizability of the results may be limited to SSA. We limited our review to studies published in English and possibly excluded a sizable number of studies reported in French and Portuguese, for instance, that met our inclusion criteria other than language. Another limitation is that the optional 'consultation exercise' of the Arksey and O'Malley framework was not conducted. Authors of the reviewed articles would have been consulted to verify what was found in the literature.

\section{Conclusion}

Our study has highlighted barriers that can impede the translation of research evidence into policy and provided information on potential solutions that can enhance the utilization of research findings into policy formulation. We noted that research has not be translated into policy mainly because of lack of capacity by policymakers to synthesize, adopt and translate evidence for policy decisions; lack of repositories for research findings, inaccessibility of research evidence and lack of high-quality usable evidence. The limited capacity of policymakers to use evidence has resulted in delayed adoption of research findings for policy formulation because policymakers are hesitant to use the evidence for policy formulation. We also noted that policies in SSA countries tend to be guided by international agencies with little consideration of local evidence.

The capacity of policymakers to use evidence for policy can be enhanced through collaboration between researchers and policymakers, skills training workshops and mentoring programmes. If researchers and policymakers co-conceptualize research and policy makers are involved during implementation of the research, policymakers will likely have confidence in the research findings and become more willing to use it for policy formulation. This will also assist researchers in understanding the policymaking process and on the other hand policymakers will be kept aware of ongoing research. Skills- training will equip policymakers with the necessary skills to identify research evidence that has policy relevance and to also distinguish research of high and low methodological quality. Mentoring will guide policymakers in the identification of policy options and subjection of these options to evidence synthesis. It can also be used to provide technical guidance to policymakers to enable them to produce policy briefs.
We conclude that research evidence remains inaccessible in SSA countries, and this can be fixed by strong collaboration between researchers and policymakers. Researchers tend to make little effort to package research findings in formats that are easily accessible to policymakers. Thus, research findings may be available locally but remain inaccessible to policymakers as they are published in international journals that are not accessible to local policymakers who need the evidence. Sometimes research reports are scattered across institutions or ethical approval bodies and that makes it difficult for policymakers to access as there are no central repositories. Policymakers do not have much time to look for research evidence from scientific journals. It is therefore important to package important findings as policy briefs that can be used during stakeholder feedback meetings and at conferences. Such interactions between researchers and policymakers may enhance uptake of research findings for policy formulation.

Unfortunately, there is currently very little of that happening as researchers make little effort to produce policy briefs and to have stakeholder feedback sessions. We also recommend funders to make it mandatory for researchers to produce policy briefs and have stakeholder feedback sessions to highlight implications of research findings on policy. Universities need to include policy brief writing in their curriculum and train postgraduate students conducting policy related research how to write policy briefs.

Lack of high-quality usable evidence may be attributed to limited local funding for research. Quite often researchers end up producing poor quality research because of limitations in the funding or they opt for funder- driven research which addresses funder priorities. Governments can support high quality research production through increasing funding allocated to health research, through investing and supporting capacity strengthening of researchers and establishing department of Research and $\mathrm{PDU}$ in the $\mathrm{MOH}$. It is imperative to have a comprehensive approach to reduce barriers whilst enhancing facilitators that may improve the translation of research findings into policy.

\section{Disclaimer}

The views and opinions expressed in this article are those of the authors and do not necessarily reflect the official policy or position of any affiliated agency of the authors.

Received: 28 July 2021; Accepted: 25 January 2022;

Published online: 28 February 2022

\section{References}

Abekah-Nkrumah G, Issiaka S, Virgil L, Ermel J (2018) A review of the process of knowledge transfer and use of evidence in reproductive and child health in Ghana. Health Res Policy Syst 16:75

Adam T, Moat KA, Ghaffar A, Lavis JN (2014) Towards a better understanding of the nomenclature used in information-packaging efforts to support evidenceinformed policymaking in low-and middle-income countries. Implement Sci 9:67

Araujo De Carvalho I, Byles J, Aquah C, Amofah G, Biritwum R, Panisset U, Goodwin J, Beard J (2014) Informing evidence-based policies for ageing and health in Ghana. Bull World Health Organ 93:47-51

Arksey H, O'malley L (2005) Scoping studies: towards a methodological framework. Int J Soc Res Methodol 8:19-32

Aryeetey R, Holdsworth M, Taljaard C, Hounkpatin WA, Colecraft E, Lachat C, Nago E, Hailu T, Kolsteren P, Verstraeten R (2017) Evidence-informed decision making for nutrition: African experiences and way forward. Proc Nutr Soc 76:589-596

Berman J, Mitambo C, Matanje-Mwagomba B, Khan S, Kachimanga C, Wroe E, Mwape L, Van Oosterhout JJ, Chindebvu G, Van Schoor V (2015) Building a knowledge translation platform in Malawi to support evidence-informed health policy. Health Res Policy Syst 13:1-5

Boaz A, Hanney S, Borst R, O'shea A, Kok M (2018) How to engage stakeholders in research: design principles to support improvement. Health Res Policy Syst $16: 1-9$ 
Bowsher G, Papamichail A, El Achi N, Ekzayez A, Roberts B, Sullivan R, Patel P (2019) A narrative review of health research capacity strengthening in low and middle-income countries: lessons for conflict-affected areas. Glob Health 15:1-13

Burris H, Parkhurst J, Adu-Sarkodie Y, Mayaud P (2011) Getting research into policy-Herpes simplex virus type-2 (HSV-2) treatment and HIV infection: international guidelines formulation and the case of Ghana. Health Res Policy Syst 9:1-10

Chu KM, Jayaraman S, Kyamanywa P, Ntakiyiruta G (2014) Building research capacity in Africa: equity and global health collaborations. PLoS Med 11:e1001612

Cockcroft A, Masisi M, Thabane L, Andersson N (2014) Building capacities of elected national representatives to interpret and to use evidence for healthrelated policy decisions: a case study from Botswana. J Public Health Policy 35:475-488

Czerniewicz L, Goodier S (2014) Open access in South Africa: a case study and reflections. S Afr J Sci 110:1-9

Czerniewicz L, Wiens K (2013) The online visibility of South African knowledge: searching for poverty alleviation: building the information society. Afr J Inf Commun 2013:30-41

De Sardan J-PO (2011) Promoting research in the face of consultancy. Cah Detudes Afr 51:511-528

Deans F, Ademokun A (2015) Investigating capacity to use evidence. International Network for the Availability of Scientific Publications (INASP).

Dobbins M, Hanna SE, Ciliska D, Manske S, Cameron R, Mercer SL, O'mara L, Decorby K, Robeson P (2009) A randomized controlled trial evaluating the impact of knowledge translation and exchange strategies. Implement Sci $4: 1-16$

El-Jardali F, Lavis J, Moat K, Pantoja T, Ataya N (2014) Capturing lessons learned from evidence-to-policy initiatives through structured reflection. Health Res Policy Syst 12:2

El-Jardali F, Mandil A, Jamal D, Boukarroum L, El-Feky S, Nour M, Al-Abbar M (2018) Engagement of health research institutions in knowledge translation in the Eastern Mediterranean Region. Eastern Mediterr Health J 24

Ellen ME, Horowitz E, Vaknin S, Lavis JN (2016) Views of health system policymakers on the role of research in health policymaking in Israel. Israel J Health Policy Res 5:24

Evans MC, Davila F, Toomey A, Wyborn C (2017) Embrace complexity to improve conservation decision making. Nat Ecol Evol 1:1588-1588

Ezenwaka U, Mbachu C, Etiaba E, Uzochukwu B, Onwujekwe O (2020) Integrating evidence from research into decision-making for controlling endemic tropical diseases in South East Nigeria: perceptions of producers and users of evidence on barriers and solutions. Health Res Policy Syst 18:4

Franzen SR, Chandler C, Lang T (2017) Health research capacity development in low and middle income countries: reality or rhetoric? A systematic metanarrative review of the qualitative literature. BMJ Open 7:e012332

Goodman MS, Sanders Thompson VL (2017) The science of stakeholder engagement in research: classification, implementation, and evaluation. Transl Behav Med 7:486-491

Grobbelaar SS, Harber T (2016) Towards the institutionalization of research uptake management in sub-Saharan African universities. J Higher Educ Africa/Rev enseignement supérieur Afrique 14:155-181

Hamel N, Schrecker T (2011) Unpacking capacity to utilize research: a tale of the Burkina Faso public health association. Soc Sci Med 72:31-38

Hanney SR, Kanya L, Pokhrel S, Jones TH, Boaz A (2020) How to strengthen a health research system: WHO's review, whose literature and who is providing leadership? Health Res Policy Syst 18:1-12

Haynes A, Rowbotham SJ, Redman S, Brennan S, Williamson A, Moore G (2018) What can we learn from interventions that aim to increase policy-makers' capacity to use research? A realist scoping review. Health Res Policy Syst $16: 1-27$

Holdsworth M, Kruger A, Nago E, Lachat C, Mamiro P, Smit K, Garimoi-Orach C, Kameli Y, Roberfroid D, Kolsteren P (2015) African stakeholders' views of research options to improve nutritional status in sub-Saharan Africa. Health Policy Plan 30:863-874

Hyder AA, Corluka A, Winch PJ, El-Shinnawy A, Ghassany H, Malekafzali H, Lim M-K, Mfutso-Bengo J, Segura E, Ghaffar A (2011) National policy-makers speak out: are researchers giving them what they need? Health Policy Plan 26:73-82

Inguane $\mathrm{C}$, Sawadogo-Lewis T, Chaquisse E, Roberton T, Ngale K, Fernandes $\mathrm{Q}$, Dinis A, Augusto O, Covele A, Hicks L (2020) Challenges and facilitators to evidence-based decision-making for maternal and child health in Mozambique: district, municipal and national case studies. BMC Health Serv Res 20:1-10

Kalbarczyk A, Rodriguez DC, Mahendradhata Y, Sarker M, Seme A, Majumdar P, Akinyemi OO, Kayembe P, Alonge OO (2021) Barriers and facilitators to knowledge translation activities within academic institutions in low-and middle-income countries. Health Policy Plan 36:728-739
Kite J, Indig D, Mihrshahi S, Milat A, Bauman A (2015) Assessing the usefulness of systematic reviews for policymakers in public health: a case study of overweight and obesity prevention interventions. Prev Med 81:99-107

Kumar MB, Taegtmeyer M, Madan J, Ndima S, Chikaphupha K, Kea A, Barasa E (2020) How do decision-makers use evidence in community health policy and financing decisions? A qualitative study and conceptual framework in four African countries. Health Policy Plan 35:799-809

Kumwenda S, El Hadji AN, Orondo PW, William P, Oyinlola L, Bongo GN, Chiwona B (2017) Challenges facing young African scientists in their research careers: a qualitative exploratory study. Malawi Med J 29:1-4

Lavis JN, Guindon GE, Cameron D, Boupha B, Dejman M, Osei EJ, Sadana R (2010) Bridging the gaps between research, policy and practice in low-and middle-income countries: a survey of researchers. Cmaj 182:E350-E361

Lavis JN, Wilson MG, Oxman AD, Lewin S, Fretheim A (2009) SUPPORT Tools for evidence-informed health Policymaking (STP) 4: Using research evidence to clarify a problem. Health Res Policy Syst 7:S4

Lee AT, Simon CA (2018) Publication incentives based on journal rankings disadvantage local publications. S Afr J Sci 114:1-3

Malla C, Aylward P, Ward P (2018) Knowledge translation for public health in low-and middle-income countries: a critical interpretive synthesis. Global Health Res Policy 3:1-12

Mapulanga P, Raju J, Matingwina T (2019) Health researchers and policy makers involvement in knowledge translation activities in Malawi. J Health Organ Manag 33:380-395

Meisel ZF, Gollust SE, Grande D (2016) Translating research for health policy decisions: is it time for researchers to join social media? Acad Med 91:1341-1343

Moher D, Liberati A, Tetzlaff J, Altman DG, Group P (2009) Preferred reporting items for systematic reviews and meta-analyses: the PRISMA statement. PLoS Med 6:e1000097

Morris SS, Cogill B, Uauy R, Maternal \& Group, C. U. S. (2008) Effective international action against undernutrition: why has it proven so difficult and what can be done to accelerate progress? The Lancet, 371:608-621

Mubyazi GM, Gonzalez-Block MA (2005) Research influence on antimalarial drug policy change in Tanzania: case study of replacing chloroquine with sulfadoxine-pyrimethamine as the first-line drug. Malar J 4:51

Mwendera C, De Jager C, Longwe H, Hongoro C, Phiri K, Mutero CM (2017) Development of a framework to improve the utilisation of malaria research for policy development in Malawi. Health Res Policy Syst 15:97

Mwendera CA, De Jager C, Longwe H, Phiri K, Hongoro C, Mutero CM (2016) Facilitating factors and barriers to malaria research utilization for policy development in Malawi. Malar J 15:512

Nabyonga-Orem J, Ssengooba F, Macq J, Criel B (2014a) Malaria treatment policy change in Uganda: what role did evidence play? Malar J 13:345

Nabyonga-Orem J, Ssengooba F, Mijumbi R, Tashobya CK, Marchal B, Criel B (2014b) Uptake of evidence in policy development: the case of user fees for health care in public health facilities in Uganda. BMC Health Serv Res 14:639

Naude CE, Zani B, Ongolo-Zogo P, Wiysonge CS, Dudley L, Kredo T, Garner P, Young T (2015) Research evidence and policy: qualitative study in selected provinces in South Africa and Cameroon. Implement Sci 10:126

Newman K (2014) What is the evidence on the impact of research on international development. UK Department for International Development (DFID), London

Ogbe E, Van Braeckel D, Temmerman M, Larsson EC, Keygnaert I, De Los Reyes Aragón W, Cheng F, Lazdane G, Cooper D, Shamu S (2018) Opportunities for linking research to policy: lessons learned from implementation research in sexual and reproductive health within the ANSER network. Health Res Policy Syst 16:123

Oliver K, Innvar S, Lorenc T, Woodman J, Thomas J (2014) A systematic review of barriers to and facilitators of the use of evidence by policymakers. BMC Health Serv Res 14:2

Organization WH (2005) Report from the Ministerial Summit on Health Research: Identify challenges, inform actions, correct inequities. World Health Organization

Organization WH (2016) Investing in knowledge for resilient health systems: strategic plan 2016-2020. World Health Organization

Oronje RN, Murunga VI, Zulu EM (2019) Strengthening capacity to use research evidence in health sector policy-making: experience from Kenya and Malawi. Health Res Policy Syst 17:101

Panisset U, Koehlmoos TP, Alkhatib AH, Pantoja T, Singh P, Kengey-Kayondo J, Mccutchen B, Miguel GBA (2012) Implementation research evidence uptake and use for policy-making. Health Res Policy Syst 10:20

Schleiff MJ, Kuan A, Ghaffar A (2020) Comparative analysis of country-level enablers, barriers and recommendations to strengthen institutional capacity for evidence uptake in decision-making. Health Res Policy Syst 18:1-12

Senkubuge F, Mayosi BM (2012) The state of the national health research system in South Africa. S Afr Health Rev 2012:141-149

Shroff Z, Aulakh B, Gilson L, Agyepong IA, El-Jardali F, Ghaffar A (2015) Incorporating research evidence into decision-making processes: researcher 
and decision-maker perceptions from five low-and middle-income countries. Health Res Policy Syst 13:70

Shroff ZC, Javadi D, Gilson L, Kang R, Ghaffar A (2017) Institutional capacity to generate and use evidence in LMICs: current state and opportunities for HPSR. Health Res Policy Syst 15:1-11

Smits PA, Denis J-L (2014) How research funding agencies support science integration into policy and practice: an international overview. Implement Sci $9: 1-12$

Ssengooba F, Atuyambe L, Kiwanuka SN, Puvanachandra P, Glass N, Hyder AA (2011) Research translation to inform national health policies: learning from multiple perspectives in Uganda. BMC Int Health Hum Rights 11:S13

Tagoe N, Molyneux S, Pulford J, Murunga VI, Kinyanjui S (2019) Managing health research capacity strengthening consortia: a systematised review of the published literature. BMJ Global Health 4:e001318

Tijssen RJ, Mouton J, Van Leeuwen TN, Boshoff N (2006) How relevant are local scholarly journals in global science? A case study of South Africa. Res Eval 15:163-174

Tzarnas S, Tzarnas CD (2015) Publish or perish, and pay-the new paradigm of open-access journals. J Surg Educ 72:283-285

Uneke CJ, Ezeoha AE, Uro-Chukwu H, Ezeonu CT, Ogbu O, Onwe F, Edoga C (2015a) Enhancing the capacity of policy-makers to develop evidenceinformed policy brief on infectious diseases of poverty in Nigeria. Int J Health Policy Manag 4:599

Uneke CJ, Ezeoha AE, Uro-Chukwu H, Ezeonu CT, Ogbu O, Onwe F, Edoga C (2015b) Promoting evidence to policy link on the control of infectious diseases of poverty in Nigeria: outcome of a multi-stakeholders policy dialogue. Health Promot Perspect 5:104

Uneke CJ, Sombie I, Keita N, Lokossou V, Johnson E, Ongolo-Zogo P (2017) Improving maternal and child health policymaking processes in Nigeria: an assessment of policymakers' needs, barriers and facilitators of evidenceinformed policymaking. Health Res Policy Syst 15:48

Uthman OA, Wiysonge CS, Ota MO, Nicol M, Hussey GD, Ndumbe PM, Mayosi BM (2015) Increasing the value of health research in the WHO African Region beyond 2015-reflecting on the past, celebrating the present and building the future: a bibliometric analysis. BMJ Open 5:e006340

Verstraeten R, Roberfroid D, Lachat C, Leroy JL, Holdsworth M, Maes L, Kolsteren PW (2012) Effectiveness of preventive school-based obesity interventions in low-and middle-income countries: a systematic review. Am J Clin Nutr 96:415-438

Witter S, Anderson I, Annear P, Awosusi A, Bhandari NN, Brikci N, Binachon B, Chanturidze T, Gilbert K, Jensen C (2019) What, why and how do health systems learn from one another? Insights from eight low-and middle-income country case studies. Health Res Policy Syst 17:1-13

Woelk G, Daniels K, Cliff J, Lewin S, Sevene E, Fernandes B, Mariano A, Matinhure S, Oxman AD, Lavis JN (2009) Translating research into policy: lessons learned from eclampsia treatment and malaria control in three southern African countries. Health Res Policy Syst 7:1-14

Yimgang D, Danhoundo G, Kusi-Appiah E, Sunder V, Campbell S, Yaya S (2021) A scoping review of researchers' involvement in health policy dialogue in Africa. Syst Rev 10:1-12

Young T, Shearer JC, Naude C, Kredo T, Wiysonge CS, Garner P (2018) Researcher and policymaker dialogue: the Policy BUDDIES Project in Western Cape Province, South Africa. BMJ Global Health 3

\section{Acknowledgements}

Our earnest thanks to Dr. T Mindu for assisting with literature searches on various databases. We would like to thank the College of Health Sciences for funding.

\section{Author contributions}

FUD, NGM and MJC conceptualized and designed the study. FUD did literature searches (verified by NMG), analysis, writing and compilation of manuscript. FUD contributed to abstract screening and full-text screening of the included studies. NGM and MJC contributed to resolving discrepancies at full-text screening and quality assessment as well as supervising the processes, reading all versions. All authors have read and approved the final article.

\section{Competing interests}

The authors declare no competing interests.

\section{Ethical approval}

This study does not contain any studies with human participants performed by any of the authors.

\section{Informed consent}

This article does not contain any studies with human participants performed by any of the authors.

\section{Additional information}

Supplementary information The online version contains supplementary material available at https://doi.org/10.1057/s41599-022-01070-2.

Correspondence and requests for materials should be addressed to Florence Upenyu Damba.

Reprints and permission information is available at http://www.nature.com/reprints

Publisher's note Springer Nature remains neutral with regard to jurisdictional claims in published maps and institutional affiliations.

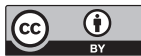

Open Access This article is licensed under a Creative Commons Attribution 4.0 International License, which permits use, sharing, adaptation, distribution and reproduction in any medium or format, as long as you give appropriate credit to the original author(s) and the source, provide a link to the Creative Commons license, and indicate if changes were made. The images or other third party material in this article are included in the article's Creative Commons license, unless indicated otherwise in a credit line to the material. If material is not included in the article's Creative Commons license and your intended use is not permitted by statutory regulation or exceeds the permitted use, you will need to obtain permission directly from the copyright holder. To view a copy of this license, visit http://creativecommons.org/ licenses/by/4.0/.

(c) The Author(s) 2022 